\title{
Biogeographical affinities of East Asian polypores
}

\author{
MARIA NƯÑEZ and JOGEIR STOKLAND
}

NÚÑEZ, M. \& STOKLAND, J.: Biogeographical affinities of East Asian polypores. Karstenia 40: 123-128. Helsinki. ISSN 0453-3402.

\begin{abstract}
A biogeographical analysis of East Asian polypores based on species lists and Dice's similarity index is provided. A comparison of the temperate East Asian polypore mycota with those from other north temperate areas showed that most species belong to the north temperate element, but East Asia has the highest biodiversity and degree of endemism of all north temperate areas. East Asia and East North America share the highest amount of taxa. Furthermore, several species with their main distribution centres in the palaeotropics, Australia, and even the neotropics, occur in East Asia. Their presence in this area could be related to past geological events.
\end{abstract}

Maria Núñez, Botanical Garden and Museum, University of Oslo, Trondheimsvn. 23B, N-0562 Oslo, Norway

Jogeir Stokland, Norwegian Institute of Land Inventory, P.O. Box 115, N-1430 As, Norway

\section{Introduction}

East Asia has without any doubt the richest, yet the less explored biodiversity among temperate areas (Latham \& Ricklefs 1993). Two main factors have contributed to preserve biodiversity in East Asia: the rising of the Qinghai/Xizang plateau in Central Asia 45 million years ago, which heavily affected the climate and vegetation of the area (Chang 1983), and the limited spread of glaciers in East Asia during the Quaternary. As a result, a continuous forest corridor from East Siberia to tropical South East Asia has existed during several million years, allowing the coexistence of temperate and tropical species (Kira 1991).

The taxonomy and distribution of polypores in Europe and North America is well documented (Gilbertson \& Ryvarden 1986-87, Ryvarden \& Gilbertson 1993-94). The knowledge of East Asian polypores has been improved in the last years by several type studies of species described from the area (Hattori \& Ryvarden 1994, Dai \& Niemelä 1995), and the publication of mycofloras and corology articles (Imazeki et al. 1988, Zhao \& Zhang 1992, Dai 1996, Dai 1999). The first volume of a polypore mycoflora of temperate East Asia has been published (Núñez \& Ryvarden 2000). Furthermore, communication between mycologists around the world has settled many taxonomic questions and led to a more uniform use of names.

Most East Asian fungi are circumpolar (Hjortstam \& Ryvarden 1982, Zhao \& Zhang 1992, Ryvarden \& Gilbertson 1993-94). Other species display an East Asia-East North America disjunction (Hongo \& Yokoyama 1978, Wu \& Mueller 1997). The sino-japanese endemic component is significant in East Asia (Imazeki et al. 1988, Dai 1996). Besides, a minor amount of East Asian species have their main distribution centre in areas historically and geologically related to temperate East Asia, as South East Asia or Australia (Núñez \& Ryvarden 1995). Plants (Hsu 1983), mosses (Vána 1992), hepatics (Piipo 1992), ferns (Iwatsuki 1994), and lichens (Jørgensen 1983) share a similar distribution pattern.

We have performed a preliminary biogeographic analysis of East Asian polypores based 
on species lists and Dice's similarity index. However, we are aware that reconstructing the historical biogeography of polypores is not possible at this stage of knowledge, as extensive fieldwork is still needed.

\section{The area covered}

This study covers the East Asia territory north of the Tropic of Cancer, i.e., the whole territory of Japan, Korea, Far East Russia (Kamchatka, Primorsk, Khabarovsk, Sakhalin, and Kunashir provinces), and most of China. We have included the northern provinces of Thailand and Vietnam, and the high mountains of Taiwan, as their polypore mycota has a marked temperate character (Hjortstam \& Ryvarden 1982, Parmasto 1986, Kiet 1998). Species from tropical China and Taiwan lowlands have been left out, since these regions belong both geographically and floristically to the tropics. The presence of Dipterocarpaceae in these areas emphasises their floristic links to the rainforests in South East Asia (Xiwen \& Walker 1986).

The limit of East Asia towards the west is not clearly settled in this study, as data from Laos, Burma, and Bhutan are almost non-existent. Further north, the natural limit has been set in the transition towards the dryer ecosystems of grasslands and deserts in Tibet and the Himalayan range, that is about $100^{\circ} \mathrm{E}$.

\section{Forests in the area}

Four main forest ecosystems are recognised in East Asia: subtropical forests, warm-temperate and mesophytic forests, cold-temperate forests, and boreal forests (Suzuki 1953, Wang 1961, Numata et al. 1972). These communities intergrade without any clear borderline, mostly depending on the local orogeny.

The mesophytic forest is the richest forest ecosystem of East Asia, including over 50 genera of broad-leaved trees and 15 genera of conifers (Latham \& Ricklefs 1993).

The subtropical and warm-temperate forests in East Asia are extremely exuberant compared to those of North America and Europe at the same latitude. In the latter continents xeric sclerophyllous forests contact with deserts lying to the South. Only in East Asia the potential forest area forms a continuous corridor from temperate to subtropical areas (see above).

\section{Materials and methods}

We have compiled species lists of polypores from Europe, western North America, eastern North America, and East Asia. Species lists are based on literature records, herbarium material at $\mathrm{O}$ and TFM, and own collecting from 1994-96 in Japan by M.N. Due to space limits, the whole species list is not included here, but it can be requested from the authors.

In order to quantify similarities in species composition between regions, we used Dice's similarity index to compare species lists according to the formula: $\mathrm{S}=2 \mathrm{c}$ / $(a+b)$. In this formula $a$ and $b$ are the number of taxa in region $\mathrm{a}$ and $\mathrm{b}$ respectively, and $\mathrm{c}$ is the number of common taxa between the two regions. The value of the index vary between 0 (no common taxa) and 1.0 (identical taxonomic composition in area $\mathrm{a}$ and $\mathrm{b}$ ).

\section{Results and discussion}

\section{The north temperate element}

A total of 119 genera and 670 polypore species have been recorded from all north temperate areas, out of which 63 genera $(52.9 \%)$ and 184 species $(27.5 \%)$ are circumpolar (Table 1$)$. The strictly circumpolar genera (viz., those where all species are circumpolar) are invariably mono- or bitypic, and are always associated with conifers, as Amylocystis (1 sp.), Climacocystis (1 sp.), Jahnoporus (1 sp.), Leptoporus (1 sp.), and Pycnoporellus ( $2 \mathrm{sp}$.). We can speculate whether these genera appeared after the Quaternary glaciation and extended rapidly with their coniferous hosts. The fact that most of them produce brown rot (except Climacocystis and Jahnoporus) can point to a recent origin of this type of rot in temperate areas, as suggested by Gilbertson (1980). This theory seems to be reinforced by the fact that the most diverse brown-rot polypore genera on coniferous hosts (Antrodia, Anomoporia, and Oligoporus) are mainly temperate, and have highest species numbers in Europe, the continent with the smallest number of endemic species.

East Asia has the highest number of genera and species among north temperate areas, followed by eastern North America. Europe, the area with lowest polypore diversity, lacks 28 genera and 131 species that occur in East Asia.

Out of the circumpolar genera (63), 18 have highest species number and degree of endemism in East Asia, compared with five in Europe, three in eastern North America, and three in western North America.

Out of the 15 most diverse genera (more than 15 species), nine have highest diversity in East 
Table 1. Number of taxa of north-temperate areas. In parentheses, number of taxa exclusive for a given area. Percentage of circumpolar taxa is shown for the total numbers of north-temperate genera and species.

\begin{tabular}{lcc}
\hline & Genera & Species \\
\hline Europe & $75(3)$ & $342(57)$ \\
Western North America & $79(0)$ & $300(28)$ \\
Eastern North America & $94(6)$ & $372(62)$ \\
East Asia & $103(16)$ & $473(152)$ \\
\hline Total / circumpolar & $119 / 52.9 \%$ & $670 / 27.5 \%$ \\
\hline
\end{tabular}

Asia (Albatrellus, Antrodiella, Fomitopsis, Ganoderma, Inonotus, Perenniporia, Phellinus, Polyporus, and Skeletocutis), four in Europe (Antrodia, Ceriporiopsis, Oligoporus and Skeletocutis), two in East North America (Trametes and Tyromyces), and none in western North America.

East Asia also has the highest amount of exclusive genera (16) and species (152), that is, genera or species that do not occur in other temperate areas (Table 1). Exclusive genera in East Asia are the endemic Castanoporus, Porodontia, and Pyrrhoderma, plus 13 tropical genera. In Europe, the exclusive genera are restricted to the endemic Lenzitella and Podofomes, both associated to the Mediterranean element. Meruliporia and Polyporoletus are the only exclusive genera for the whole North America, but both are also found in tropical America. Exclusive genera in East North America are the endemic Globifomes, plus five tropical genera. Western North America itself does not have any exclusive genus.

Four pantropical genera occur in East Asia, but not in North America (Amauroderma, Echinochaete, Grammothele, Loweporus), while only two occur in North America, and not in East Asia (Diacanthodes, Navisporus). Apparently, the deserts lying south for North America constitute an effective barrier for tropical species migrating towards the north, while the continuous forest corridor between tropical and temperate Asia allows more effectively the migration of tropical species towards temperate East Asia.

\section{Global affinities of East Asian polypores}

Table 2 gives the approximate global distribution of East Asian polypores. The criterion to define the distribution of certain genera and species had to be subjective in several cases, as we still
Table 2. Global distribution of East Asian polypores.

\begin{tabular}{lcc}
\hline Distribution pattern & Genera & Species \\
\hline Cosmopolitan & 39 & 51 \\
Circumpolar & 29 & 184 \\
Eurasian & 1 & 25 \\
Endemic & 3 & 68 \\
East Asia - East North America & 5 & 21 \\
Pantropical & 17 & 80 \\
Palaeotropical + East Asia & 2 & 35 \\
Western Pacific & 7 & 9 \\
TOTAL & 103 & 473 \\
\hline
\end{tabular}

miss distribution data from large areas of the world.

Most East Asian species are circumpolar (184), followed by a high amount of pantropical species (80), and East Asian endemisms (68). The amount of Eurasian species (25) is almost similar to the amount of East Asia - East North America disjunct species (21). Nine species with main distribution centre in the Australian continent occur in East Asia. Two species only previously known from the neotropics have been found in East Asia (see below).

The high presence of tropical genera in temperate East Asia has been reported before (Parmasto 1983). As an example, one species of the palaeotropical genus Microporus, M. vernicipes, extends up to Far East Russia. Other examples of tropical polypores occurring in temperate East Asia are Ceriporia mellea and Phellinus glaucescens. The South East Asian Phylloporia bibulosa and Whitfordia spathulata reach subtropical China and Japan.

A mesophytic forest very similar to the one in the southern parts of cold-temperate East Asia covers the Southern Appalachians in eastern North America (Kryshtofovich 1929, Fernald 1931, Hsu 1983). Several temperate polypore species have a disjunct distribution in these two areas: Cryptoporus volvatus, Fomitopsis palustris, Ganoderma lobatum, Inonotus ludovicianus, Perenniporia ellipsospora, $P$. robiniophila, $P$. variegata, Trametes conchifer, and Wolfiporia dilatohypha. Besides, there are several examples of vicarious species between East North America (ENA) - East Asia (EA) of genera that do not occur in Europe: Coltriciella oblectabilis (ENA) - C. pusilla (EA), Echinodontium ballouii (ENA) - E. japonicum (EA), and Echinoporia aculeifera (ENA) - E. hydnophora (EA). 
The temperate genus Melanoporia, deserves special attention. This genus is only known from eastern North America and East Asia, with one species in East North America (M. nigra, resupinate), and one in East Asia (M. castanea, mainly triquetrous). Other genera with a high number of East Asia - East North America disjunct species are Fomitopsis, Perenniporia, Phellinus, Phylloporia, Trametes, and Wolfiporia. The disjunct species between East Asia and East North America are believed to be a relict element from the Tertiary that survived in both regions during the Quaternary glaciations (Hsu 1983, Jørgensen 1983, Vána 1992).

Several polypore species with main distribution centre in the Australian continent occur in temperate East Asia, viz. Coltriciella tasmanica, Heterobasidion insulare, Inonotus setulosocroceus, Laccocephalum hartmanni, Pycnoporus coccineus, and the genus Elmerina (Núñez 1998). During the Quaternary glaciations, continental South-East Asia extended eastwards up to Bali. Besides, numerous islands in the western Pacific have connected temperate Asia and Australia since the Australian continent started to drift towards Asia 15 million years ago.

The records of Polyporus guianensis and P. leprieurii in East Asia, only previously known from the neotropics, are more difficult to interprete. Two theories are available: 1 ) these species were initially pantropical, and disappeared from Africa as this continent became dryer on its migration to the north 2) these species have migrated to East Asia through the southern Hemisphere via Australia.

Sharp (1972) already stated that several plant species show an East Asia - northern Latin America distribution.

\section{Similarities between regions}

In our study, East Asia and East North America share the highest number of both genera and species, but do not have the highest similarity index. Wu \& Mueller (1997) reported a similar phenomenon when they analysed the difference in macrofungi between temperate areas using Simpson's coefficient index. Our explanation is that Dice's similarity index is influenced by the degree of heterogeneity of the mycota we compare. The more homogeneous two areas are the higher their similarity index. In the case of East Asia and East North America, the heterogeneity
Table 3. Number of shared taxa between different northtemperate areas. In parentheses, Dice's similarity index (see the text).

\begin{tabular}{lcc}
\hline & Genera & Species \\
\hline $\begin{array}{l}\text { Eastern North America } \\
\text { - Western North America }\end{array}$ & $74(0.86)$ & $247(0.74)$ \\
$\begin{array}{l}\text { Europe } \\
\text {-Western North America }\end{array}$ & $69(0.90)$ & $223(0.69)$ \\
$\begin{array}{l}\text { Europe } \\
- \text { Eastern North America }\end{array}$ & $67(0.79)$ & $227(0.64)$ \\
$\begin{array}{l}\text { Europe - East Asia } \\
\text { East Asia }\end{array}$ & $69(0.78)$ & $255(0.63)$ \\
$\begin{array}{l}\text { Western North America } \\
\text { East Asia }\end{array}$ & $72(0.79)$ & $230(0.60)$ \\
- Eastern North America & $82(0.83)$ & $265(0.63)$ \\
\hline
\end{tabular}

is due to the tropical species that reach East Asia and East North America. Many or them are endemic for each tropical region, that is, they are either palaeotropical or neotropical. The amount of tropical species is high in both areas, and this fact biases the value of Dice's similarity index.

Among north-temperate areas, Europe and western North America show the highest similarity index at genus level (0.90, Table 3$)$. Both areas have had a similar history during and after Quaternary glaciations, with many species being wiped away as glaciers spread towards the south. It is reasonable to suppose that the present polypore mycota in both areas is the result of new establishments after the glaciations. Nevertheless, a higher similarity index between eastern and western North America (0.74) than between Europe and western North America (0.69) seems to indicate that American species spread successfully throughout the whole North America during the post- glacier period, while several Eurasian species failed to cross the Atlantic ocean barrier.

The lowest similarity index at species level is displayed between East Asia and western North America (0.60). Land continuity between these two areas disappeared when the Bering Strait opened, and it seems that long distance dispersal has failed in spreading most species across this channel.

The advantage of migrating across continuous land contra long distance dispersal is again highlighted as East Asia and Europe have a higher similarity index (0.63) than East Asia and West North America (0.60). The migration of Asian species towards Europe may have occurred after the glaci- 
ations. Most of the migrating Asian species must have belonged to the temperate element, as no tropical Asian taxa are known in Europe.

Temperate East Asia has retained much of the vegetation that inhabited Eurasia during the late Tertiary (Hsu 1983). During the Pliocene glaciations, the continuous Eurasian forest belt broke. Several species survived in relict localities in the Scandinavian 'nunataks', the Caspian area, and the Mediterranean mountains (Kvacek et al. 1989). One possible example in polypores may be Piloporia sajanensis, whose known distribution area comprises the Changbai Mountains (North China), the Caspian area, Central Finland and Sweden, and the high mountains in Sardinia (Bernicchia \& Ryvarden 1997).

Acknowledgements. Leif Ryvarden and Tsutomu Hattari have been central in allowing us to attain a better knowledge of East Asian polypores.

\section{References}

Bernicchia, A.R. \& Ryvarden, L. 1997: Piloporia sajanensis (Parmasto) Niemelä, a boreal rare polypore new to Italy. - Mycologia Helvetica 9: 85-89.

Chang, M.S. 1983: The Tibetan plateau in relation to the vegetation of China. Ann. Miss. Bot. Gard. 70: 564-570.

Culberson, W.L. 1972: Disjunctive distributions in the lichen-forming fungi. - Ann. Miss. Bot. Gard. 59: $165-173$

Dai, Y.C. 1996: Changbai wood-rotting fungi 7. A checklist of the polypores. - Fung. Sci. 11: 79-105.

Dai, Y.C. 1999: Phellinus sensu lato (Aphyllophorales, Hymenochaetaceae) in East Asia. - Acta Bot. Fennica 166: 1-115.

Dai, Y.C. \& Niemelä, T. 1995: Changbai wood-rotting fungi 4. Some species described by A.S. Bondartsev and L.V. Lyubarsky from the Russian Far East. - Ann. Bot. Fennici 32: 211-226.

Fernald, M.L. 1931: Specific segregations and identities in some floras of eastern North America and the old world. - Rhodora 33: 25-62.

Gilbertson, R.L. 1980: Wood-rotting fungi of North America. - Mycologia 72: 1-49.

Gilbertson, R.L. \& Ryvarden, R 1986: North American Polypores 1: 1-433. - Fungiflora, Oslo.

Gilbertson, R.L. \& Ryvarden, R. 1987: North American Polypores 2: 434-885. - Fungiflora, Oslo.

Graham, A. 1972: Outline of the origin and historical recognition of floristic affinities between Asia and eastern North America. - In: Graham, A. (ed.). Floristics and paleofloristics of Asia and eastern North America: 1-16.

Hattori, T. \& Ryvarden, L. 1994: Type studies in the Polyporaceae 25. Species described from Japan by R.
Imazeki and A. Yasuda. - Mycotaxon 50: 27-46.

Hjortstam, K. \& Ryvarden, L. 1982: Aphyllophorales from Northern Thailand. - Nord. J. Bot. 2: 273-281.

Hongo, T. \& Yokoyama, K. 1978: Mycofloristic ties of Japan to the continents. - Memoirs of Shiga University $28: 76-80$.

Hsu, J. 1983: Late cretaceous and cenozoic vegetations in China, emphasizing their connections with North America. - Ann. Miss. Bot. Gard. 70: 490-508.

Imazeki, R. Otani, Y. \& Hongo, T. 1988: Fungi of Japan. - Yama-Kei, Tokyo. 623 pp.

Iwatsuki, K. 1994: Comparison of pteridophyte flora between North America and Japan. - In: Miyawaki, A., Iwatsuki, K. \& Grandtner, M.M. (eds.) Vegetation in eastern North America: 89-97. University of Tokyo Press, Tokyo.

Jørgensen, P.M. 1983: Distribution patterns of lichens in the Pacific Region. - Aust. J. Bot. Suppl. Ser. 10: 141.

Kato, M. \& Iwatsuki, K. 1983: Phytogeographic relationships of pteridophytes between temperate North America and Japan. - Ann. Miss. Bot. Gard. 70: 724733.

Kiet, T.T. 1998: Charakteristika der Großpilzflora Vietnams. - Feddes Repert. 109: 249-256.

Kira, T. 1991: Forests ecosystems of East and Southeast Asia in a global perspective. - Ecol. Res. 6: 185-200.

Kryshtofovich, A.N. 1929: Evolution of the tertiary flora in Asia. - New Phytologist 28: 303-312.

Kvacek, Z., Walther, H. \& Buzek, C. 1989: Paleogene floras of W. Bohemia (C.S.S.R.) and the Wiesselster Basin (G.D.R.) and their correlation. - Casopis pro Mineralogii a Geologii 34: 385-402.

Latham, R.E. \& Ricklefs, R.E. 1993: Continental comparisons of temperate-zone tree species diversity. In: Ricklefs, R.E. \& Schluter, D. (eds.). Species diversity in ecological communities. Historical and geographical perspectives: 294-311. The University of Chicago Press.

Numata, J., Mayawaki, A. \& Itow, D. 1972: Natural and semi-natural vegetation in Japan. - Blumea 20: 435496.

Núñez, M. 1998: The genus Elmerina in Japan. - Folia Cryptog. Estonica 33: 99-101.

Núñez, M. \& Ryvarden, L. 1995: Polypores new to Japan 1. Species of Polyporus, with a note on P. hartmanii. - Mycoscience 36: 61-65.

Núñez, M. \& Ryvarden, L. 2000: East Asian polypores. Ganodermataceae and Hymenochaetaceae. - Fungiflora, Oslo. $168 \mathrm{pp}$.

Parmasto, E. 1983. Leucophellinus mollissimus, a tropical polypore found in Soviet Far East. - Eesti NSV Tead. Akad. 32, Ser. Biol. 4: 269-272.

Parmasto, E. 1986: Preliminary list of Vietnamese Aphyllophorales and Polyporaceae s. str. - Acad. Sci. Estonian SSR Inst. Zool. Bot. Scripta Mycologica. 88 pp.

Piippo, S. 1992: On the phytogeographical affinities of temperate an tropical Asiatic and Australasian hepatics. - J. Hattori Bot. Lab. 71: 1-35.

Renliang, H. 1990: Distribution of bryophytes in China. - Tropical Bryology 2: 133-137.

Ryvarden, L. \& Gilbertson, R.L. 1993: European Polypores 1: 1-393. - Fungiflora, Oslo. 
Ryvarden, L. \& Gilbertson, R.L. 1994: European Polypores 2: 394-743. - Fungiflora, Oslo.

Sharp, A.J. 1972: The possible significance of some exotic distributions of plants occurring in Japan and/or North America. - In: Graham, A. (ed.). Floristics and paleofloristics of Asia and eastern North America: 61-64. - Elsevier Pub. Comp., Amsterdam.

Suzuki, T. 1953: The forest climaxes of East Asia. Jap. J. Bot. 14: 1-12.

Vána, J. 1992: Notes on the taxonomy and phytogeography of the family Jungermanniaceae in East Asia. Bryobrothera 1: 289-292.
Wang, C.W. 1961: The forests of China (with a survey of grassland and desert vegetation). - Maria Moors Cabot Foundation 5: 1-313. Harvard University, Cambridge, Massachusetts.

Wu, Q. \& Mueller, M. 1997: Biogeographic relationships between the macrofungi of temperate eastern Asia and eastern North America. - Can. J. Bot. 75: 2108-2116.

Xiwen, L. \& Walker, D. 1986: The plant geography of Yunnan Province, southwest China. - J. Biogeography 13: 367-397.

Zhao, J.D. \& Zhang, X.Q. 1992: The polypores of China. - Bibliotheca Mycologica 145: 1-524. 